\title{
PENGEMBANGAN KAMPOENG WISATA CINANGNENG BERDASARKAN TIPOLOGI WISATAWAN
}

\author{
DEVELOPMENT OF KAMPOENG WISATA CINANGNENG BASED ON TOURIST \\ TIPOLOGY
}

\author{
Syawaliyah Ulfah \\ Fakultas Pariwisata Universitas Pancasila \\ Srengseng Sawah, Jagakarsa, Jakarta Selatan 12640 \\ Telepon/fax: +62 2178885779
}

\begin{abstract}
Bogor Regency of West Java Province that is developing the potential of its territory for tourist destination and attract the attention of local and foreign tourists to visit. The location that researcher has been choosed to do research is Kampoeng Wisata Cinangneng which is located in Bogor regency. Kampoeng Wisata Cinangneng located in the village of Cihideung Udik, Ciampea District has a tourism concept based on nature tourism and educational tourism. The purpose of this research are to identify the development component of the destination (factual conditions in the field), identify the tourist tipology who visit Kampoeng Wisata Cinangneng and develop strategies Kampoeng Tourism Development Cinangneng based on tourist tipology. This research is a descriptive quantitative and descriptive qualitative research. Quantitative research is conducted to determine the tourist characteristics and tourist tipology that calculated by used percentages. Qualitative research is conducted to find out the development strategy in Kampoeng Wisata Cinangneng. Generally qualitative research method is intended for research that is observed case. The collected data will be analyzed using SWOT analysis, followed by compiling alternative strategies using SWOT matrix. Kampoeng Wisata Cinangneng has a good enough strength to be developed based on the tourist tipology, but the nature and culture of the existing tourism has not been maximally utilized, although it has a good accessibility, less complete amenitas, condition of supporting facilities is complete enough. The result of typology is that tourists who visit Kampoeng Wisata Cinangneng tend to mid-centric tipology. Based on the results of SWOT analysis bring out an alternative strategy that is: Invite local people to teach tourists to make souvenirs that them make, adding outbound packages to be variants that can be offered to tourists, make a places to eat in the middle of rice field with food from local community.
\end{abstract}

Keywords: Tourism Development, Tourist Tipology 


\begin{abstract}
ABSTRAK
Kabupaten Bogor Provinsi Jawa Barat yang sedang mengembangkan potensi wilayahnya untuk tujuan wisata dan menarik perhatian para wisatawan lokal maupun mancanegara untuk berkunjung. Lokasi yang peneliti pilih untuk melakukan penelitian adalah Kampoeng Wisata Cinangneng yang berada di Kabupaten Bogor. Kampoeng Wisata Cinangneng yang berada di desa Cihideung Udik, Kecamatan Ciampea memiliki konsep wisata yang berbasiskan wisata alam dan wisata edukasi. Tujuan dari penelitian ini adalah mengidentifikasi komponen pengembangan destinasi (kondisi factual di lapangan), mengidentifikasi tipologi wisatawan yang berkunjung ke Kampoeng Wisata Cinangneng dan menyusun strategi Pengembangan Kampoeng Wisata Cinangneng berdasarkan Tipologi wisatawan. Penelitian ini merupakan jenis penelitian deskriptif kuantitatif dan deskriptif kualitatif. Penelitian secara kuantitatif dilakukan untuk mengetahui karakteristik wisatawan dan tipologi wisatawan yang dihitung dengan menggunakan persentase. Penelitian kualitatif dilakukan untuk mengetahui strategi pengembangan di Kampoeng Wisata Cinangneng. Pada dasarnya metode penelitian kualitatif ditujukan untuk penelitian yang bersifat mengamati kasus. Data yang yang terkumpul akan dianalisis menggunakan analisis SWOT, dilanjutkan dengan menyusun strategi alternatif menggunakan matriks SWOT. Kampoeng Wisata Cinangneng memiliki kekuatan yang cukup baik untuk dikembangkan berdasarkan tipologi wisatawan, namun wisata alam dan budaya yang ada belum dimanfaatkan secara maksimal, meskipun memiliki aksesibilitas yang cukup baik, amenitas yang kurang begitu lengkap, kondisi fasilitas pendukung yang cukup lengkap, serta keberadaan kelembagaan walau belum berperan dengan maksimal. Hasil tipologi yang didapat ialah wisatawan yang berkunjung ke Kampoeng Wisata Cinangneng cenderung bertipologi mid-centric. Berdasarkan hasil analisis SWOT memunculkan alternatif strategi yaitu: Mengajak masyarakat setempat untuk mengajarkan wisatawan membuat souvenir yang mereka buat, menambah paket outbond untuk menjadi varian yang dapat ditawarkan kepada wisatawan, membuat saung-saung untuk makan ditengah sawah dengan makanan hasil masak masyarakat setempat.
\end{abstract}

Kata Kunci : Pengembangan Pariwisata, Tipologi Wisatawan.

\section{PENDAHULUAN}

Pariwisata merupakan salah satu hal yang penting bagi suatu negara. Dengan adanya pariwisata, suatu negara atau lebih khusus lagi pemerintah daerah tempat daya tarik wisata itu berada mendapat pemasukan dari pendapatan setiap daya tarik wisata. Berkembangnya sektor pariwisata disuatu negara akan menarik sektor lain untuk berkembang pula karena produk-produknya diperlukan untuk menunjang industri pariwisata. Seperti sektor pertanian, peternakan, perkebunan, kerajinan rakyat, peningkatan kesempatan kerja, dan lain sebagainya. Mata rantai kegiatan yang terkait dengan industri pariwisata tersebut mampu menghasilkan devisa dan dapat pula digunakan sebagai sarana untuk menyerap tenaga kerja sehingga dapat mengurangi angka pengangguran dan meningkatkan angka kesempatan kerja.

Kabupaten Bogor merupakan salah
satu wilayah $\quad$ yang $r$ sedang
mengembangkan potensi wilayahnya
untuk tujuan wisata dan menarik


perhatian para wisatawan lokal maupun mancanegara untuk berkunjung. Salah satu daya tarik wisata yang ada di Kabupaten Bogor yang akan diteliti oleh peneliti ialah kampung wisata Cinangneng

Wisatawan yang mengunjungi Kampoeng Wisata Cinangneng sangat bervariasi karakternya dan mempunyai keperluan yang berbeda-beda, dimulai dari rentang usia dan pendidikan serta pola perjalanan mereka yang berbedabeda. Pelaksanaan paket wisata atau program wisata yang sudah dibuat oleh pengelola tersebut, terjadi pada saat wisatawan yang bervariasi karakteristiknya membutuhkan susunan aktivitas yang komplit, memberikan pengalaman yang maksimal, memberikan kemudahan atau kepraktisan dalam pembeliannya dan sesuai dengan kebutuhan wisatawan itu sendiri, yang dihadapkan dengan ketidakpastian pengelola dalam menyiapkannya (Wirakusuma dan Mulyani 2016).

Berdasarkan judul yang telah diambil oleh peneliti yakni "Pengembangan Kampoeng Wisata Cinangneng Berdasarkan Tipologi Wisatawan" Peneliti melakukan penelitian di Kampoeng Wisata Cinangneng dan akan membuat strategi pengembangan yang baik untuk Kampoeng Wisata Cinangneng yaitu berdasarkan teori Sunaryo (2013) yaitu komponen pengembangan destinasi ada lima antara lain adalah :

- Attraction

- Accessibility

- Amenities

- Ancillary

- Institutions
Wisatawan mempunyai berbagai macam tipologi, model aktivasi kepribadian wisatawan ini memperluas teori Plog (1972) yang asli karena dapat menghasilkan tipe wisatawan yang lebih banyak lagi . Atas dasar ini Plog (1972) mengembangkan tipologi wisatawan sebagai berikut : Allocentric, psychocentric, midcentric (Damasdino 2015).

Kegiatan pariwisata atau kunjungan wisatawan nusantara yang terjadi di Kabupaten Bogor dari tahun 2012 sampai tahun 2016, dengan meningkatnya jumlah wisatawan dari tahun ke tahun tentunya akan berdampak positif untuk pendapatan daerah Kabupaten Bogor, peningkatan kualitas hidup, dan kesejahteraan masyarakat lokal. Tidak hanya berdampak positif saja melainkan dampak negatif juga akan dirasakan oleh masyarakat Kabupaten Bogor. Tetapi pada wisatawan mancanegara jumlah wisatawan mengalami pasang surut yang sangat mencolok dilihat dari jumlah kunjungan dari tahun ke tahun. Dengan banyaknya kunjungan wisatawan ini, Kabupaten Bogor harus mengembangkan dan meremajakan destinasinya sesuai dengan permintaan wisatawan (konsumen).

Salah satu penyebab Kampung wisata Cinangneng Bogor menjadi sorotan wisatawan adalah Kampung Wisata Cinangneng menjadi pelopor wisata edukasi di Kabupaten Bogor yang sudah lama berdiri. Salah satu alasan tersebut dapat menarik wisatawan untuk mengunjungi Kampoeng Wisata Cinangneng.

pasang surut kunjungan wisatawan nusantara dan wisatawan manacanegara yang mengunjungi Kampoeng Wisata Cinangneng, dari tahun 2012 ke tahun 2013 mengalami peningkatan wisatawan 
nusantara, tetapi wisatawan mancanegara mengalami penurunan jumlah kunjungan. Ditahun 2014, wisatawan nusantara dan wisatawan mancanegara mengalami penurunan dari tahun sebelumnya. Pada tahun 2015 terjadi peningkatan kunjungan wisatawan nusantara tetapi tidak untuk wisatawan mancanegara, ditahun 2016 wisatawan nusantara dan wisatawan mancanegara mengalami penurunan jumlah kunjungan dari tahun sebelumnya. Sangat terlihat dengan jelas peningkatan dan penurunan jumlah wisatawan yang mengunjungi Kampoeng Wisata Cinangneng, hal tersebut yang menjadi dasar peneliti untuk melakukan penelitian tentang Tipologi wisatawan di Kampoeng Wisata Cinangneng dalam mengembangkan wisatanya. Dengan menganalisis tipologi wisatawan, peneliti dapat mengetahui karakter atau tipologi wisatawan yang mengunjungi Kampoeng wisata Cinangneng.

Berdasarkan latar belakang tersebut dapat dirumuskan masalah

1. Bagaimana kondisi existing dari Kampoeng Wisata Cinangneng menurut wisatawan.

2. Bagaimana tipologi wisatawan yang berkunjung ke Kampoeng Wisata Cinangneng.

3. Bagaimana strategi pengembangan Kampoeng Wisata Cinangneng berdasarkan tipologi wisatawan.

\section{TUJUAN PENELITIAN}

Menjabarkan kondisi existing dari Kampoeng Wisata Cinangneng, Mengidentifikasi tipologi wisatawan yang mengunjungi Kampung Wisata Cinangneng, Membuat strategi pengembangan Kampoeng Wisata Cinangneng berdasarkan tipologi wisatawan.

\section{METODE PENELITIAN}

Lokasi yang dipilih untuk melakukan penelitian adalah Kampung Wisata Cinangneng yang beralamat di Jalan Babakan Kemang, RT 01 / RW 02, Cihideung Udik, Kecamatan Ciampea, Kabupaten Bogor, Jawa Barat. Lokasi dipilih secara sengaja dengan pertimbangan bahwa Kampung Wisata Cinangneng sangat potensial untuk dikembangkan lagi mengingat Kampung Wisata Cinangneng sudah cukup lama berdiri dan belum melakukan pengembangan.

Desain penelitian ini adalah dengan menggunakan pendekatan deskriptif kualitatif dan deskriptif kuantitatif. Penelitian ini merupakan jenis penelitian deskriptif kuantitatif dan deskriptif kualitatif. Penelitian secara kuantitatif dilakukan untuk mengetahui karakteristik dan tipologi wisatawan yang dihitung dengan menggunakan persentase. Penelitian secara kualitatif dilakukan mengetahui upaya pengembangan Kampoeng Wisata Cinangneng. Desain penelitian ini peneliti melakukan wawancara secara mendalam, observasi serta menyebarkan kuisioner kepada wisatawan, studi dokumentasi, untuk menghimpun data kata (teks) atau gambar (foto) (Indrawan dan Yaniawati 2014).

Jenis data yang digunakan adalah data dengan menggunakan pendekatan kualitatif dan pendekatan kuantitatif (mixed methods), sumber data pada penelitian ini terbagi menjadi dua, yaitu data primer dan data skunder.

1. Data primer adalah data yang didapat melalui proses observasi, penyebaran kuisioner dan wawancara mendalam pada responden yang memiliki kompetensi terkait lokasi tersebut. 
2. Data sekunder adalah data yang diperoleh melalui data di luar observasi dan wawancara, seperti publikasi pemerintah, berita di media, majalah, dan sebagainya. Sumber data pada penelitian ini adalah informan dan kawasan. Informan merupakan sumber dari data yang dihimpun dengan cara melakukan wawancara mendalam. Sedangkan kawasan merupakan sumber dari data yang akan dihimpun melalui observasi.

Pengumpulan data pada penelitian ini menggunakan pendekatan kualitatif. Dan pendekatan kuantitatif teknik pengumpulan data dan informasi yang lazim digunakan dalam pendekatan kualitatif dan kuantitatif (mixed methods), adalah observasi, wawancara mendalam, penyebaran kuisioner (Indrawan dan Yaniawati 2014:133).

\section{Observasi}

Peneliti akan melakukan observasi di Kampung Wisata Cinangneng terkait dengan menganalisa tipologi wisatawan dan upaya pengembangan Kampung Wisata Cinangneng sabagai daya tarik wisata, khususnya melihat potensi yang dimiliki kawasan tersebut sebagai daya tarik wisata. Observasi yang akan peneliti lakukan adalah observasi langsung yaitu peneliti secara fisik datang di lokasi penelitian untuk berinteraksi secara langsung dengan wisatawan serta masyarakat sekitar Kampung Wisata Cinangneng untuk menggali informasi sebanyak-banyaknya terkait permasalahan yang ada.

2. Wawancara

Wawancara dilakukan secara mendalam kepada pihak yang terlibat dalam pengelolaan kawasan Kampoeng Wisata Cinangneng dan masyarakat lingkungan sekitar terkait pengembangan kawasan tersebut sebagai daya tarik wisata. Sedangkan wawancara yang peneliti lakukan adalah wawancara terbuka dan mendalam kepada pengelola Kampoeng Wisata Cinangneng, wisatawan yang mengunjungi KAmpoeng Wisata Cinangneng serta masyarakat yang mempunyai peran penting. Yaitu wawancara yang tidak terstruktur dan terpaku pada panduan wawancara sehingga dapat menggali data selengkap mungkin dari narasumber (Indrawan dan Yaniawati 2014).

\section{Kuisioner}

Sejumlah pertanyaan tertulis yang digunakan untuk memperoleh informasi dari responden tentang pribadinya atau penilaian dirinya atas sesuatu (Indrawan dan Yaniawati 2014). Penyebaran kuisioner dilakukan oleh peneliti kepada wisatawan untuk mendapatkan informasi mengenai kondisi existing di Kampoeng Wisata Cinangneng yang berupa atraksi, aksesibilitas, amenitas, fasilitas penunjang dan kelembagaan serta untuk mendapatkan informasi mengenai tipologi wisatawan yang mengunjungi Kampoeng Wisata Cinangneng. Jenis kuisionernya adalah kuisioner tertutup dan menggunakan skala Guttman. Kuisioner tertutup adalah kuisioner yang pilihan jawabannya hanya dua yaitu ya dan tidak. Menurut Sugiyono (2012:139) penelitian menggunakan skala Guttman dilakukakan bila ingin jawabannya yang tegas terhadap suatu permasalahan yang ditanyakan.

\section{ANALISIS DATA}

Dalam penelitian ini analisis data yang dilakukan dengan menggunakan pendekatan kualitatif, penelitian ini menggunakan analisis SWOT untuk mengidentifikasi kekuatan, kelemahan, 
peluang dan ancaman di Kampoeng Wisata Cinangneng. Data yang sudah terkumpul akan diolah dan menghasilkan sebuah upaya pengembangan. Penilit akan mengolah data kedalam matriks SWOT.

\section{HASIL DAN PEMBAHASAN}

Lokasi penelitian dilaksanakan di Kampoeng Wisata Cinangneng. Kampoeng Wisata Cinangneng beralamat di jalan Babakan Kemang, RT 01/ RW 02, Cihideung Udik, yang berada di kaki Gunung Salak dan dialiri sungai Cinangneng yang merupakan anak Sungai Cisadane. Kecamatan Ciampea, kabupaten Bogor, Jawa Barat. Kampoeng Wisata Cinangneng yang berada pada ketinggian 600-900 meter dari permukaan laut dan suhu rata-rata sebesar 24,3 C, menjadikannya sebagai lokasi wisata yang nyaman dengan udaranya yang sejuk. Kampoeng Wisata Cinangneng adalah suatu wisata yang berasaskan wisata edukasi dengan daya tarik utamanya yaitu wisata alam. Peneliti akan melakukan penelitian mengenai pengembangan Kampoeng Wisata Cinangneng berdasarkan tipologi wisatawan yang mana peneliti akan mengidentifikasi terlebih dahulu komponen-komponen pengembangan menurut Sunaryo tahun 2013 dan kondisi faktual yang ada di Kampoeng Wisata Cinangneng.

\section{Atraksi}

Atraksi alam di Kampoeng Wisata Cinangneng seperti area pesawahan yang menjadi wisata edukasi untuk para wisatawan bagaimana cara menanam padi, memandikan kerbau dan sebagainya juga menjadi hal yang menarik bagi wisatawan yang sehari-harinya tinggal di kota dan ingin merasakan kebudayaan serta alam yang berada di Kampoeng Wisata Cinangneng. Kampoeng Wisata Cinangneng mempunyai produk unggulan yang ditawarkan kepada wisatawan. Berdasarkan wawancara dengan pengelola Kampoeng Wisata Cinangneng produk tersebut adalah program Poelang Kampoeng, yang mana wisatawan diajak beraktivitas layaknya masyarakat seperti menanam padi, bermain alat musik Gamelan dan memandikan kerbau. Salah satu yang menjadi highlight Kampoeng Wisata Cinangneng adalah aktivitas yang memandikan kerbau di sungai, untuk itu ikon atau simbol dari Kampoeng Wisata Cinangneng adalah 2 kerbau yang ada disetiap sudut Kampoeng Wisata Cinangneng.

\section{Aksesibilitas}

Jika wisatawan menggunakan angkutan umum dan menggunakan moda transportasi kereta api, wisatawan turun di stasiun Bogor lalu menggunakan kendaraan umum bernomor 02 atau 03 menuju terminal Laladon. Setelah sampai terminal, wisatawan menggunakan angkot tumaritis yang menuju langsung ke Kampoeng Wisata Cinangneng. Jarak menuju Kampoeng Wisata Cinangneng

a) Jarak menuju Kampoeng Wisata Cinangneng dari pusat kota Bogor ialah $\pm 11 \mathrm{~km}$ dengan lama perjalan 27 menit atau \pm satu setengah jam perjalanan dengan menggunakan kendaraan pribadi maupun kendaraan umum atau bus pariwisata.. Jika wisatawan menggunakan bus pariwisata atau menggunakan kendaraan pribadi wisatawan dapat keluar tol Pajajaran atau keluar tol Sentul jarak tempuhnya sama yaitu \pm 13 
km menuju Kampoeng Wisata Cinangneng.

b) Papan petunjuk jalan menuju Kampoeng Wisata Cinangneng Papan penunjuk jalan menuju Kampoeng Wisata Cinangneng cukup jelas dan dimengerti, namun ukuran papan penunjuk jalan yang menunjukkan lokasi Kampoeng Wisata Cinangneng sedikit kecil, dikhawatirkan akan tidak terlihat oleh wisatawan yang baru pertama kali mengunjungi Kampoeng Wisata Cinangneng. Kondisi jalan menuju Kampoeng Wisata Cinangneng

c) Kondisi jalan menuju Kampoeng Wisata Cinangneng cukup baik dan bagus, jalanan tidak ada yang rusak maupun berlubang. Tetapi, pada saat hari libur wisatawan akan terkena sedikit kemacetan di arah Universitas IPB Dramaga.

\section{Amenitas}

Berdasarkan hasil observasi peneliti mengenai amenitas yang ada di Kampoeng Wisata Cinangneng cukup lengkap dengan adanya penginapan, restoran dan toko cinderamata, namun seperti penginapan hanya tersedia di dalam Kampoeng Wisata Cinangneng saja. Penginapan seperti hotel terdekat Kampoeng Wisata Cinangneng jaraknya berkisar 3 kilometer. Artinya, jika wisatawan ingin berkunjung ke Kampoeng Wisata Cinangneng namun tidak ingin menggunakan akomodasi yang disediakan Kampoeng Wisata Cinangneng, wisatawan harus mencari penginapan diluar kawasan Kampoeng Wisata Cinangneng. Selanjutnya terdapat restoran dan toko cinderamata milik Kampoeng Wisata Cinangneng yang mana dapat menunjang Kampoeng Wisata Cinangneng dalam melakukan kegiatan pariwisata.

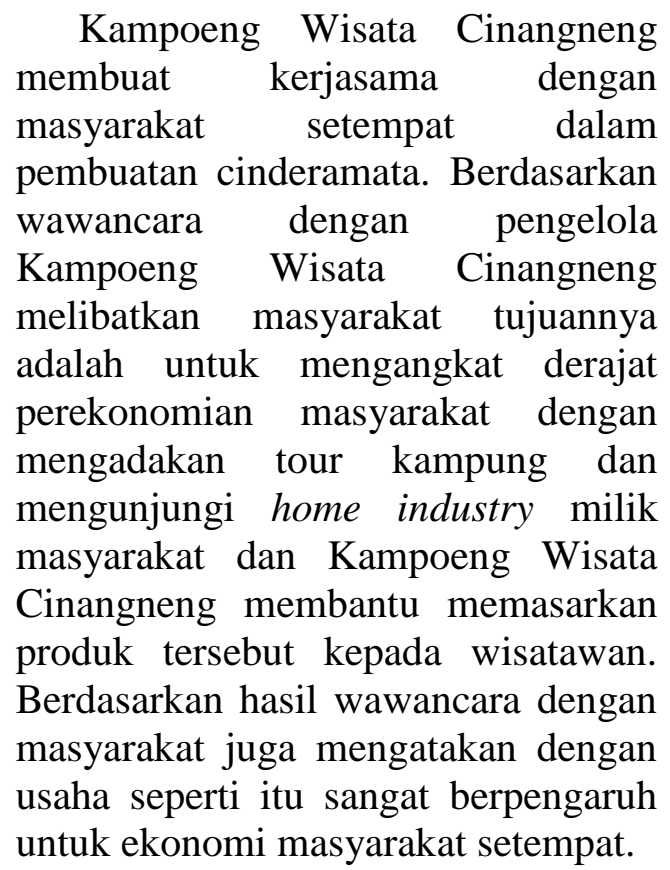

\section{Fasilitas Pendukung}

Fasilitas pendukung juga mempunyai peran penting untuk terlaksananya kegiatan wisata dan tentunya untuk wisatawan. Fasilitas pendukung di sekitaran Kampoeng Wisata Cinangneng seperti Rumah sakit, Kantor Polisi, ATM, dan sebagainya berada tidak jauh dari lokasi Kampoeng Wisata Cinangneng.

\section{Kelembagaan}

Karyawan-karyawan yang bekerja di Kampoeng Wisata Cinangneng juga merupakan mayoritas dari masyarakat sekitar yang diberdayakan oleh pengelola Kampoeng Wisata Cinangneng, menjadi sumber daya manusia yang ikut andil dalam upaya 
pengembangan Kampoeng Wisata Cinangneng, yang mana karyawankaryawan tersebut diberi pelatihanpelatihan untuk meningkatkan kualitas diri dalam menghadapi wisatawan domestik maupun wisatawan mancanegara yang berkunjung.

\section{TIPOLOGI WISATAWAN}

Berdasarkan hasil kuisioner yang telah disebarkan oleh peneliti untuk wisatawan mengenai jenis Tipologi wisatawab apa yang mayoritas mengunjungi Kampoeng Wisata Cinangneng yaitu :

1. Allocentric wisatawan yang mengunjungi Kampoeng Wisata Cinangneng yang menjawab ya sekitar $36 \%$ dan yang menjawab tidak $64 \%$. Untuk itu cenderung bukan bertipologi allocentric berdasarkan hasil presentase.

2. Midcentric wisatawan yang mengunjungi Kampoeng Wisata Cinangneng yang menjawab ya sekitar $77 \%$. dan yang menjawab tidak $23 \%$ Untuk itu wisatawan yang berkunjung ke Kampoeng Wisata Cinangneng cenderung bertipologi mid-centric berdasarkan hasil presentase.

3. Psychocentric

wisatawan yang mengunjungi Kampoeng Wisata Cinangneng yang menjawab ya sekitar $47 \%$. dan yang menjawab tidak 53\% Untuk itu wisatawan yang berkunjung ke Kampoeng Wisata Cinangneng cenderung bukan bertipologi psychocentric berdasarkan hasil presentase
Kesimpulan dari hasil penelitian mengenai Tipologi wisatawan adalah Jumlah responden sebanyak 30 orang, setiap variabel Tipologi wisatawan terdapat 4 buah pertanyaan. Berikut adalah data hasil Tipologi wisatawan :

Tabel 4.6

Jumlah hasil Tipologi Wisatawan

\begin{tabular}{|c|c|c|c|c|c|c|}
\hline Pertanyaan Ke & \multicolumn{2}{|c|}{ Allocentric } & \multicolumn{2}{|c|}{ Mid-centric } & \multicolumn{2}{c|}{ Psychocentric } \\
\hline \multirow{2}{*}{ Pertanyaan Pertama } & Ya & Tidak & Ya & Tidak & Ya & Tidak \\
\cline { 2 - 7 } & 8 & 22 & 29 & 1 & 22 & 8 \\
\hline Pertanyaan Kedua & 15 & 15 & 27 & 3 & 18 & 12 \\
\hline Pertanyaan Ketiga & 7 & 23 & 19 & 11 & 7 & 23 \\
\hline Pertanyaan Keempat & 13 & 17 & 19 & 11 & 20 & 10 \\
\hline JUMLAH & $\mathbf{4 3}$ & 77 & $\mathbf{9 4}$ & 26 & $\mathbf{6 7}$ & 53 \\
\hline PRESENTASE & $\begin{array}{l}43+94+67 \times 100 \\
=21 \%\end{array}$ & & $\frac{94}{43+94+67 \times 100}$ \\
$=46 \%$ & & $\frac{67}{43+94+67 \times 100}$ & \\
$=33 \%$ & \\
\hline
\end{tabular}

umber : Hasil Analisis

Diasumsikan bahwa jawaban "ya" tersebut mewakili Tipologi dari responden yang mengunjungi Kampoeng Wisata Cinangneng, dan jumlah jawaban "ya" dari setiap tipologi di presentasikan dengan jumlah masing-masing Tipologi.

Berdasarkan hasil yang telah ditemukan, tipologi wisatawan yang mengunjungi Kampoeng Wisata Cinangneng mayoritas adalah mid-centric yang artinya adalah wisatawan yang berkunjung ke Kampoeng Wisata Cinangneng memiliki kecenderungan mewakili seseorang dan menyukai destinasi atau atraksi wisata yang disukai oleh allocentric namun mereka tidak terlalu menyukai atraksi wisata yang bersifat petualangan. 


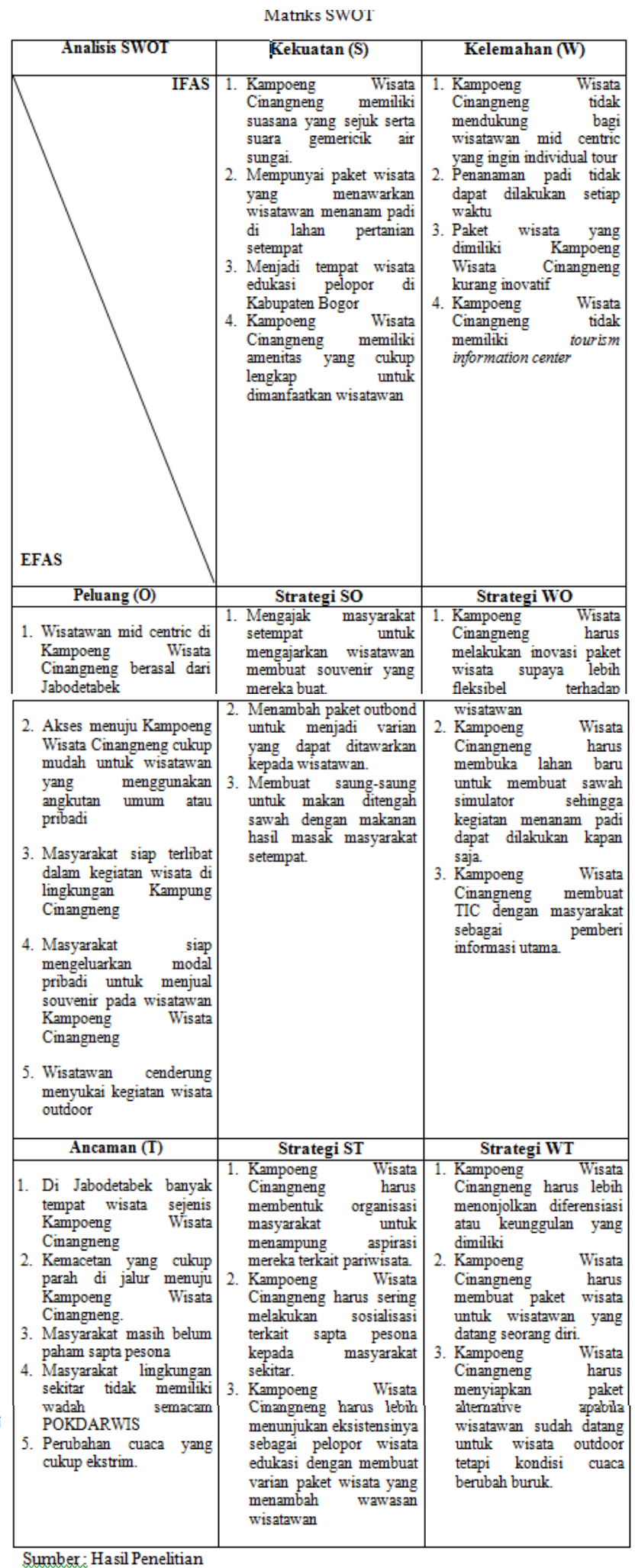

Sumber: Hasil Penelitian
Alternatif strategi yang dipilih untuk mengembangkan Kampoeng Wisata Cinangneng berdasarkan Tipologi wisatawan adalah strategi SO. Dipilihnya strategi SO adalah karena besarnya kekuatan yang dimiliki Kampoeng Wisata Cinangneng menjadi daya tarik wisata yang dimintai oleh wisatawan, untuk merebut dan memanfaatkan peluang sebesar-besarnya.

Strategi SO tersebut adalah :

1. Mengajak masyarakat setempat untuk mengajarkan wisatawan membuat souvenir yang mereka buat.

* Tipologi mid-centric sangat menyukai destinasi yang masih alami alamnya, maupun kehidupan sosial yang berada di destinasi tersebut. Dengan temuan hasil penelitian, bahwa wisatawan yang mengunjungi Kampoeng Wisata Cinangneng cenderung bertipologi midcentric,untuk itu Kampoeng Wisata Cinangneng perlu memberikan himbauan atau edukasi kepada masyarakat dalam mengajak masyarakat agar wisatawan dapat terlibat dan mengajarkan wisatawan membuat souvenir yang mereka buat.

2. Menambah paket outbond untuk menjadi varian yang dapat ditawarkan kepada wisatawan.

* Sudah seharusnya Kampoeng Wisata Cinangneng berinovasi dalam pengadaan paket wisata yang mereka punya. Khususnya memfokuskan paket wisata berdasarkan permintaan pasar yaitu midcentric. Salah satu contohnya yaitu menambah paket outbound untuk wisatawan 
seperti penambahan atraksi buatannya salah satunya yaitu flying fox, dan permainan air dan memanfaatkan sumber daya alam yang tersedia yaitu seperti menambahkan rafting di sungai Cinangneng.

3. Membuat saung-saung untuk makan ditengah sawah dengan makanan hasil masak masyarakat setempat.

* Kampoeng Wisata Cinangneng harus memaksimalkan kekuatan yang ada yaitu masyarakat siap terlibat dalam kegiatan wisata di Kampoeng Wisata Cinangneng. Dengan memberdayakan masyarakat untuk melakukan kegiatan masak-memasak makanan tradisional untuk wisatawan yang berkunjung, dan wisatawan dapat menikmati makanan yang dibuat oleh masayarakat sambil menikmati suasana pedesaan, serta Kampoeng Wisata Cinangneng dapat menambahkan saungsaung di tengah sawah untuk wisatawan menikmati masakan hasil masyarakat sambil menikmati suasana di Kampoeng Wisata Cinangneng

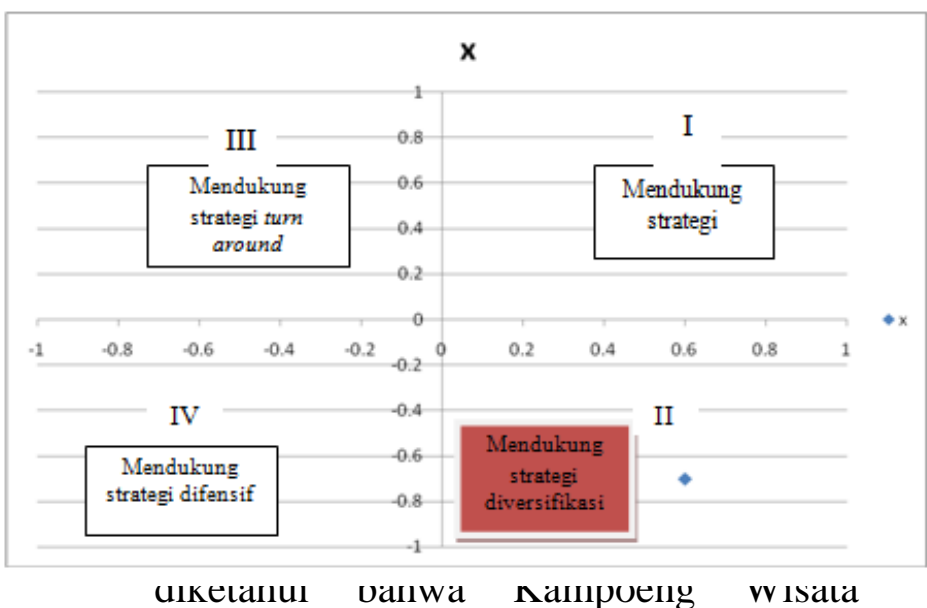

ulkelantu vallwa nallpueng vvisala
Cinangneng Berada pada kuadran 2. Kuadran 2 artinya strategi yang harus diterapkan adalah menggunakan kekuatan untuk memanfaatkan peluang jangka panjang dengan cara strategi diversifikasi (Produk/Pasar). Diversifikasi produk artinya adalah pengembangan produk dan jasa yang dimiliki oleh Kampoeng Wisata Cinangneng agar Kampoeng Wisata Cinangneng mempunyai beragam produk (varian) atau paket wisata, serta menghindari ketergantungan pada produk lama yang telah ditawarkan kepada wisatawan, dengan cara memaksimalkan kekuatan internal yang dimilki oleh Kampoeng Wisata Cinangneng untuk mendapatkan peluang yang sebesarbesarnya dan meminimalkan kekurangan serta dengan cara menginovasi paketpaket wisata yang dimiliki oleh Kampoeng Wisata Cinangneng, memfokuskan produk atau paket wisata sesuai dengan permintaan pasar (wisatawan), seperti membuat atraksi buatan olahraga air, atau kegiatan wisata yang memanfaatkan kehidupan masyarakat setempat.

\section{KESIMPULAN}

Hasil identifikasi kondisi existing di Kampoeng Wisata Cinangneng, bahwa atraksi yang dimiliki Kampoeng Wisata Cinangneng sudah mencakup atraksi alam dan atraksi budaya namun kondisi alam dan budaya yang belum dimanfaatkan semaksimal mungkin oleh Kampoeng Wisata Cinangneng. Untuk aksesibilitas menuju Kampoeng Wisata Cinangneng sudah cukup baik karena mudah untuk dijangkau dan terdapat angkutan umum yang digunakan wisatawan untuk berkunjung ke Kampoeng Wisata 
Cinangneng namun ada kendala untuk menuju ke Kampoeng Wisata Cinangneng yaitu kemacetan yang tidak dapat dihindari. Sedangkan untuk amenitas yang terdapat di Kampoeng Wisata Cinangneng masih terdapat kekurangan sehingga perlu ditambahkan oleh Kampoeng Wisata Cinangneng seperti TIC (tourism information center). Terkait dengan ketersediaan fasilitas pendukung pariwisata sudah tersedia dengan cukup baik, serta untuk kelembagaan sudah tersedia hanya saja belum mampu menjalankan perannya secara maksimal. Sedangkan untuk kelembagaan yang terdapat di Kampoeng Wisata Cinangneng sudah memerankan posisi/jabatan nya sesuai dengan yang sudah ditetapkan.

Untuk menjawab Tipologi wisatawan yang berkunjung ke Kampoeng Wisata Cinangneng adalah cenderung yang bertipologi mid-centric sesuai dengan hasil penelitian dengan menyebarkan kuisioner kepada wisatawan.

Selanjutnya, untuk menjawab terkait strategi pengembangan Kampoeng Wisata Cinangeneng berdasarkan Tipologi wisatawan, sesuai dengan hasil SWOT bahwa ditemukan hasil strategi pengembangan sebagai berikut :

- Mengajak masyarakat setempat untuk mengajarkan wisatawan membuat souvenir yang mereka buat.

- Menambah paket outbond untuk menjadi varian yang dapat ditawarkan kepada wisatawan.

- Membuat saung-saung untuk makan ditengah sawah dengan makanan hasil masak masyarakat setempat.

\begin{abstract}
Berdasarkan hasil analisis menggunakan kuadran SWOT menunjukan bahwa Kampoeng Wisata Cinangneng berada pada posisi kuadran 2 yaitu mendukung strategi diversifikasi, yang artinya adalah Kampoeng Wisata Cinangneng dalam mengembangkan tempat wisatanya dengan cara membuat inovasi paket wisata (produk) dengan memfokuskan paket wisata tersebut berdasarkan permintaan pasar agar tidak bergantung kepada produk lama yang telah ditawarkan kepada wisatawan.
\end{abstract}

\section{SARAN}

Berdasarkan hasil penelitian yang dilakukan di Kampoeng Wisata Cinangneng dengan melakukan observasi, Penyebaran kuisioner pada wisatawan dan wawancara kepada pengelola Kampoeng Wisata Cinangneng, masyarakat yang mempunyai industri rumahan cinderamata yang masingmasing dari mereka dari mereka memiliki peran masing-masing pada pariwisata di Kampoeng Wisata Cinangneng. Saran yang peneliti berikan pada Kampoeng Wisata Cinangneng antara lain :

- Pihak pengelola dan masyarakat setempat harus mempererat hubungan komunikasi dan saling berkoordinasi dalam pengembangan Kampoeng Wisata Cinangneng serta dalam memberdayakan masyarakat yang terlibat.

- Pengelola Kampoeng Wisata Cinangneng harus lebih sensitif/peka terhadap permintaan pasar dan menginovasi/mengupdate paket wisata yang sudah 
terlalu lama tidak pernah diubah.

- Pengelola Kampoeng Wisata Cinangneng harus lebih sering mengadakan penyuluhan terkait sapta pesona supaya warga semakin sadar akan kebersihan lingkungant.

- Masyarakat setempat harus membuat wadah seperti POKDARWIS untuk menyampaikan aspirasi ataupun suara yang berkaitan dengan pariwisata khususnya untuk Kampoeng Wisata Cinangneng.
Pembangunan Destinasi Pariwisata Konsep dan

Aplikasinya di Indonesia. Yogyakarta ID: PENERBIT GAVA MEDIA.

Mulyani A \& Wirakusuma MR .2016.Perencanaan Paket Wisata Berdasarkan Karakteristik dan Motivasi Wisatawan Yang Datang Ke Kampung Cireundeu Kota Cimahi.(ID). Jurnal Manajemen Resort dan Leisure.Vol.13, No.2, Oktober 2016.

\section{DAFTAR PUSTAKA}
Damasdino, Fian.2015. Studi Karakteristik Wisatawan Dan Upaya Pengembangan Produk Wisata tematik Di Pantai Goa Cemara, Pantai Kuwaru, Dan Pantai Pandansimo Baru Kabupaten Bantul (ID). Jurnal Media Wisata,Volume 13,Nomor 2,November 2015.
Indrawan R \& Yaniawati P. 2014.
METODOLOGI PENELITIAN
Kuantitatif,Kualitatif, dan Campuran untuk Manajemen, Pembangunan, dan Pendidikan.Bandung (ID): REFIKA ADITAMA.
Ross, GF.1998. Psikologi Pariwisata.Jakarta (ID): yayasan Obor Indonesia

Sugiyono. 2012. Metode Penelitian Kuantitatif Kualitatif dan R\&D. Bandung (ID):Alfabeta

Sunaryo, B. 2013. Kebijakan 